\title{
Age, gender, socioeconomic, and ethnic differences in patients' assessments of primary health care
}

\author{
J L Campbell, J Ramsay, J Green
}

\begin{abstract}
Background-Patients' evaluations are an important means of measuring aspects of primary care quality such as communication and interpersonal care. This study aims to examine variations in assessments of primary care according to age, gender, socioeconomic, and ethnicity variables.

Methods-A cross sectional survey of consecutive patients attending 55 inner London practices was performed over a 2 week period using the General Practice Assessment Survey (GPAS) instrument which assesses 13 important dimensions of primary care provision. Variations in scale scores were investigated for differences relating to age, gender, socioeconomic, and ethnic status as reported by respondents.
\end{abstract}

Results-A total of 7692 questionnaires were returned $(71 \%$ response rate). Valid information on age, gender, socioeconomic status, and ethnicity was available for 4819 out of 5496 adult respondents. Approximately half the respondents reported their ethnic group as "white" and most of the remaining respondents reported belonging to "black" or South Asian groups. Significant differences existed between groups of patients defined by age or ethnicity for most of the scale scores examined. Black, South Asian, and Chinese respondents reported lower scores (representing less favourable assessments) than white respondents; older respondents reported more favourable evaluations of care than younger respondents; and less affluent groups reported lower scores than more affluent groups for two of the 13 dimensions. There was no significant difference between gender groups with respect to assessment of primary care. Age and ethnicity were independent predictors of respondents' assessments of primary care.

Conclusions-Differences exist between identifiable subgroups of the population in their assessments of primary health care measured using the GPAS instrument. This work adds to the literature on variation in healthcare experience and the potential for patient assessment of primary care. Further work is required to investigate these differences in more detail and to relate them to differences in the nature and process of primary care provision. Primary care providers need to ensure that services provided are appropriate for all patient groups within their communities.

(Quality in Health Care 2001;10:90-95)

Keywords: primary health care; ethnicity; inequality; quantitative methodology

There are well reported differences in health status and experience between gender, age, socioeconomic, and ethnic groups within the UK population. ${ }^{1}$ Given these variations, it is essential that the health care needs and provision of patients from all sociodemographic subgroups are addressed..$^{2-8}$ As the front line of the health service, and the provider of $90 \%$ of formal health care, primary care has a key role to play in developing an equitable health service, responsive to the needs of different population groups. Reducing inequalities in health care provision and improving the quality of primary care through reducing unacceptable variations in provision have been central and recurring themes of present government health reforms. Providing care that is acceptable to patients and reducing barriers to access are cornerstones of improving quality in primary care. This is a challenge as there are well recognised differences between sociodemographic groups in the use of

Key messages

- Primary care has a key role to play in developing an equitable health service responsive to the needs of different population groups.

- Patients' evaluations are an important means of assessing whether such needs are being met, but few studies have conducted large scale comprehensive and systematic research in this area.

- GPAS is a useful instrument for measuring patients' assessments of primary care.

- This study provides evidence from a large scale survey that primary care services are evaluated less positively by younger patients and those from ethnic minorities.

- Further work is needed to relate these assessments to aspects of actual service provision and to expectations of services provided.

- Primary care providers need to ensure that services provided are appropriate for all patient groups within their communities. 
general practitioner services ${ }^{9}{ }^{10}$ and in reported priorities for the planning of general practice care. ${ }^{11}$ In addition, patient groups vary in their perceptions of difficulties encountered in accessing high quality primary care services. ${ }^{12}$ They do, however, share perceptions of the key attributes of good quality primary care, prioritising aspects such as the personal nature of care, technical competence among health professionals, and a collaborative approach to decision making. ${ }^{13} 14$

There has been increasing interest in using patient assessment to evaluate these components of primary care. Patient assessments are the most direct way of measuring aspects such as accessibility, communication, and interpersonal care, and there is evidence that patients can make valid assessments of technical competence, ${ }^{15-17}$ although it is recognised that patient assessment may be only weakly related to other measures of clinical expertise. ${ }^{18}$ In addition, patient evaluations have been shown to relate to other outcomes of primary care such as their "compliance" with medical advice and treatment. ${ }^{19}$

This study aims to examine differences between groups of patients defined by age, gender, socioeconomic, and ethnic status with respect to 13 important dimensions of primary care measured using the General Practice Assessment Survey (GPAS).

\section{The General Practice Assessment Survey (GPAS)}

The GPAS questionnaire (appendix 1) comprises seven multiple item scales and two single item scales addressing nine key areas of primary care activity (access to care, technical aspects of care, communication, interpersonal care, trust, doctor's knowledge of the patient, nursing care, services provided by receptionists, and continuity of care provided by patient's usual doctor). A further four single items relate to the patient's perception of the general practitioner's role in referral and coordination of care, their willingness to recommend their general practitioner, and their overall satisfaction with the care received. Detailed results relating to the performance of the GPAS in this study are reported elsewhere..$^{20}$ Scaled scores (out of 100) for the nine multiple item scales and four individual items were calculated for each respondent. ${ }^{21}$ These scales (higher scores representing better perceptions of care) reflect the dimensions of care identified as important in previous research on patients' evaluations of, and satisfaction with, primary care. ${ }^{14}{ }^{1522}$ A full version of the GPAS questionnaire may be seen on the Internet. ${ }^{23}$

\section{Methods}

As part of a large study examining the quality of primary care provision in an inner city setting, ${ }^{24} 11000$ consecutive patients attending one of 55 inner London practices over a 2 week period in 1998-9 were invited to complete the GPAS. Patients were asked for sociodemographic information relating to age, gender, home ownership and car availability, and ethnicity. Results obtained from young
Table 1 Ethnic groups as defined in the 1991 UK census

White

Black Caribbean

Black African

Black other

Indian

Pakistani

Bangladeshi

Chinese

Any other ethnic group

people under the age of 16 or their accompanying adults were excluded from this analysis. Respondents were allocated to one of four age categories: 16-30 years, 31-45 years, 46-60 years, and 61 years or older. A score of socioeconomic status was derived from responses to questions on home ownership and car availability. ${ }^{25}$ This allowed definition of three socioeconomic groups: the advantaged (owning or purchasing their own home and normally having access to a car), those of modest means (either owning or purchasing their own home or normally having access to a car), and the less affluent (neither owning nor purchasing their own home nor normally having access to a car). The 1991 census question on ethnicity was used to define respondent's ethnic grouping. This allocates respondents to one of nine ethnic groups on the basis of self-classification (table 1). ${ }^{26}$

In four practices analysis of response rates among adult attenders was carried out by counting the number of consecutive attenders for whom a questionnaire was available. Information on age and gender was available for comparison of responders and nonresponders.

Analysis of variance was used to compare differences in GPAS scores between populations defined by age, gender, socioeconomic status, and ethnicity. Multiple regression was used to determine the significance of age group, gender, socioeconomic status, and ethnic group after adjusting for all of these variables. Since a large number of statistical tests were being applied to the data, Bonferroni's correction was applied with significant association being determined where $\mathrm{p}<0.001$, rather than the more usual $\mathrm{p}<0.05$.

Statistical analysis was undertaken using SPSS and STATA software. Ethical approval for this study was obtained from local research ethics committees.

\section{Results}

Questionnaires were obtained from 7692 subjects ( $71 \%$ response rate). Of these, 4819 were over 16 years and had provided comprehensive information on age, gender, socioeconomic and ethnic status. Self-defined ethnicity was reported as white $(n=3014,63 \%)$; black, all groups $(\mathrm{n}=1140,24 \%)$; South Asian, all groups $(n=421,9 \%)$; Chinese $(n=39,1 \%)$; and other ethnic groups $(n=168,3 \%)$. Detailed analysis of response rates among adult attenders in four practices showed that responders were of similar age to non-responders (43.7 (19.7) years $v 45.0$ (22.0) years, $t=0.661$, $\mathrm{p}=0.51$ ), and that a greater proportion of 


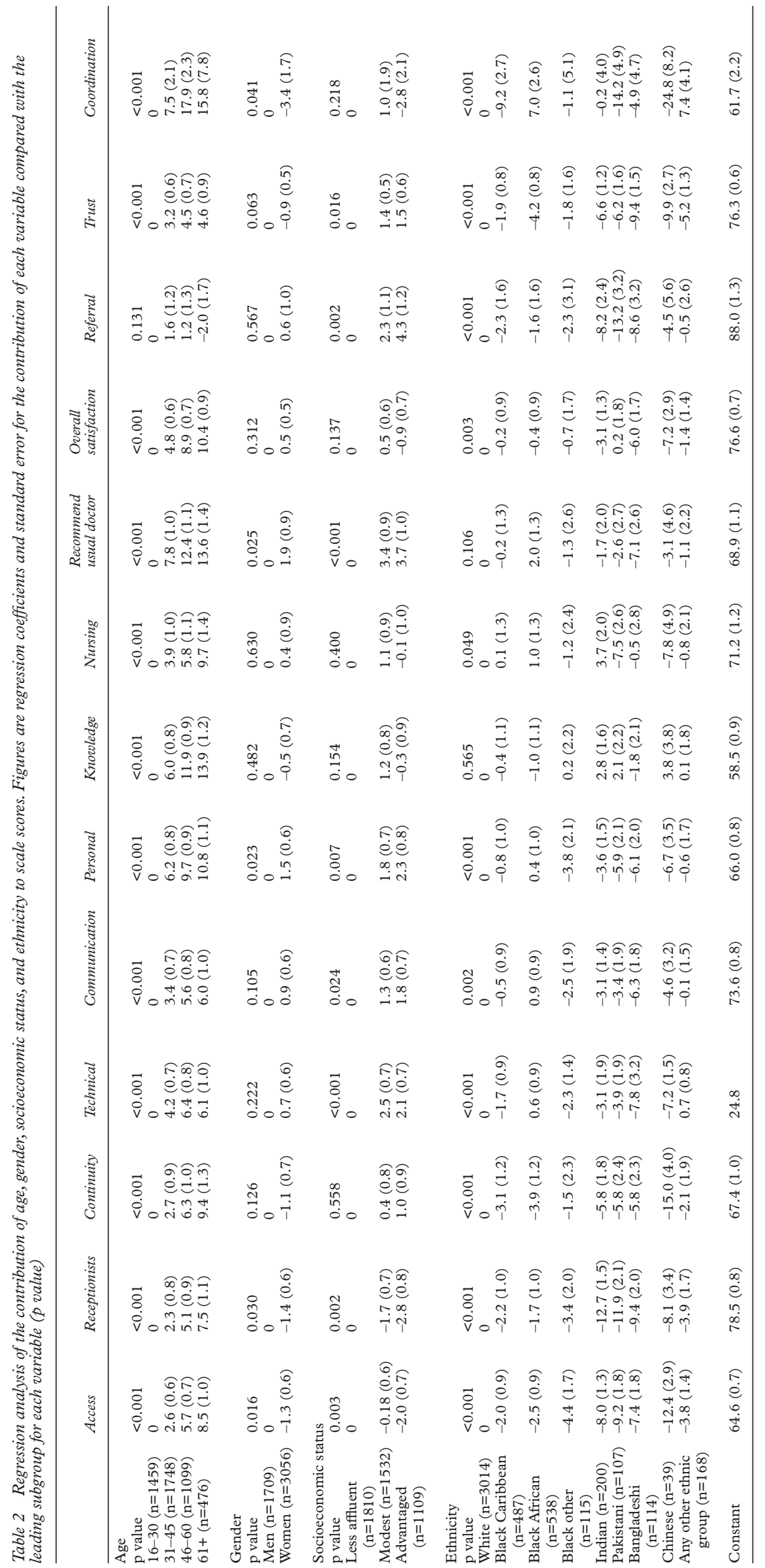

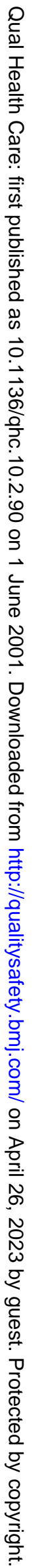


responders were women $(220 / 282(78 \%)$ male response rate $v 375 / 437(86 \%)$ female response rate, $\left.\chi^{2}=7.3, p<0.01\right)$.

Detailed GPAS scale scores have been presented elsewhere. ${ }^{20}$ In regression analysis (table 2), age and ethnicity were independent predictors of scale responses for 12 and eight of the 13 scales, respectively. In contrast, gender was not an independent predictor of scale responses and socioeconomic status was a predictor for only two scales.

Significant differences between age groups are evident for all except one (referral) of the GPAS scales, with older respondents reporting more favourable impressions for all the dimensions examined. Particularly marked differences are evident in relation to the doctor's reported knowledge of the patient, willingness to recommend their usual doctor, doctor's role in coordinating care, overall satisfaction, and the assessment of interpersonal aspects of the nature of care.

Differences between men and women were generally small, attaining statistical significance for none of the domains examined. Patients who were less affluent had lower GPAS scores for two scales than those who were more advantaged.

Differences in scores between ethnic groups were evident for eight of the 13 scales examined. White respondents consistently reported more favourable scores in each of the domains examined than those from other ethnic groups. Respondents from black ethnic groups tended to give intermediate responses while those from the Indian, Pakistani, or Bangladeshi communities tended to report lowest scores. In particular, substantial differences existed between ethnic groups in relation to the reported performance of reception staff, the perceived accessibility of care, and the trust between doctor and patient.

\section{Discussion}

This study has shown significant differences between people of varying age and ethnicity with respect to their assessments of primary care using a reliable and valid instrument to measure patients' views. Differences between people of varying socioeconomic status were less marked and were negligible for patient groups defined by gender. In regression analysis, age and ethnicity were independent predictors of patients' assessments of primary care. More research is needed to determine the extent to which these differences reflect variations in the provision of primary care across the population. The major limitation of using a cross sectional survey to examine differences in assessments of care between subgroups in the population is difficulty in distinguishing three potential explanations of differences. These are (1) that differences in reported assessments reflect actual differences in quality or appropriateness of primary care delivery, (2) that differences in reported assessments reflect cultural differences between and within population groups in willingness to report unfavourable assessments, and (3) that differences in reported assessments reflect variation in expectations of or needs for primary care between and within population groups.

AGE

Older patients rated care more favourably than younger patients in all domains examined. Given the well reported association between age and favourable perception of care ${ }^{27-29}$ this finding may reflect cultural differences in willingness to report unfavourable assessments among older patients. However, actual differences between the youngest and oldest age groups examined were often substantial, and trends in scores were evident for all except "referral" of the 13 dimensions of primary care considered. Higher morbidity and consulting rates among older patients may mean that this group may have more contact with primary care and thus have more opportunity to be favourably influenced by the services provided. Alternatively, younger patients may be perceived as somehow having less legitimacy in using primary care services and this may be being communicated to, or perceived by, such patients.

GENDER

Although men and women make very different use of primary care (with adult women having substantially greater consultation rates across all illness categories in the Fourth National Morbidity Survey ${ }^{70}$ and women being more likely than men to consult if they have an illness episode ${ }^{31}$ ), there were no significant differences between men and women in GPAS scale scores after correction for other variables under investigation.

\section{SOCIOECONOMIC STATUS}

In this study a score of socioeconomic status was derived from responses to questions on housing tenure and car ownership. ${ }^{25}$ Less affluent individuals differed from the more advantaged in reporting less favourable assessments of two dimensions of primary care (their impression of their doctor's technical ability and willingness to recommend their usual doctor). Overall, differences in socioeconomic status accounted for a relatively small amount of variability in patient assessment of care.

\section{ETHNICITY}

Overall, $37 \%$ of respondents in the study identified themselves as being from non-white ethnic minorities. In line with the census question, no inferences can be drawn about the origin of respondents from the "other" ethnic groups which make up $0.5 \%$ of residents of Great Britain. ${ }^{26}$ Non-white ethnic minority respondents reported less favourable assessments of care than white ethnic majority respondents for all except two of the 13 dimensions of care examined. Differences were most marked in the performance of reception staff (where Asian respondents reported the least favourable assessments), in the reported accessibility of care, and in the evaluation of trust between patient and doctor. Curtis and Lawson ${ }^{32}$ have 
recently reported on the poorer health experience of Afro-Caribbeans-especially AfroCaribbean women in London-but did not relate this to the accessibility and use of primary care by this population group. It is possible that the poorer perceptions of the accessibility of primary care reported here by South Asian respondents might, for example, be related to the reported lack of access to women practitioners as well as to administrative and language barriers known to be a deterrent to service uptake in other areas. ${ }^{33}{ }^{34}$ While there have been no studies of the ethnic status of reception staff, experience suggests that the majority of such members of the primary healthcare team are drawn from the white ethnic majority - which perhaps accounts, at least in part, for the lower scores on this domain by members of non-white ethnic minorities compared with the white majority. Ensuring representation of ethnic minorities among reception staff in areas of high ethnic mix might be a means of addressing this issue.

Given the differing needs for primary care of specific ethnic communities, it is likely that reported differences in assessments of quality reflect inadequacies in the provision of appropriate care.

\section{Conclusion}

In a large survey of primary care patients in London we found significant differences in assessments of services between subgroups of the population. Of particular concern are the less favourable assessments given by younger groups and those from ethnic minority groups. It is likely that these may reflect inequalities in the provision of appropriate primary care services. More research is needed to determine whether these differences reflect variation in the provision of care, greater expectations of services, or merely differences in reporting behaviour. Where it is unlikely that variations do not result from differences in reporting behaviour, primary care providers need to consider how to provide services appropriate for all patient groups within their community.

The authors are grateful to all members of participating practices for their involvement in this work, to Dr Richard
Hooper (statistician), and to referees for comments received. Hooper (statistician), and to referees for comments received. The research was funded by North Thames NHS Executive, Department of Health, London. Permission for use of the Gen-
eral Practice Assessment Survey was given by Professor Martin eral Practice Assessment Survey was given by Professor Martin Roland, Director, University of Manchester, National Primary Care Research
Health Institute.

1 Drever F, Whitehead M. Mortality in regions and local authority districts in the 1990s: exploring the relationship with deprivation. Population Trends 1995;82:19-26.

2 MacIntyre S, Hunt K, Sweeting H. Gender differences in health: are things really as simple as they seem? Soc Sci Med 1996;42:617-24.

3 Smith J, Harding S. Mortality of women and men using alternative social classifications. Health inequalities: decennial supplement. DS Series No 15. London: The Stationery Office, 1997

4 Prescott-Clarke P, Primatesta P. Health survey for England 1996. London: The Stationery Office, 1998

5 Emslie C, Hunt K, MacIntyre S. Gender differences in minor morbidity among full time employees of a British minor morbidity among full time employees of a British
university. $\mathcal{F}$ Epidemiol Community Health 1999;53:465-75.
6 Huff N, Macleod C, Ebdon D, et al. Inequalities in mortality and illness in Trent NHS Region. F Publ Health Med 1999; 21:81-7.

7 McCormick A, Fleming D, Charlton J. Morbidity statistics from general practice. Fourth national study 1991-1992. London: OPCS, 1995.

8 Vallance P, Martin J. Drug therapy for coronary heart disease: the Sheffield table. Lancet 1997;350:1854.

9 Farooqi A. How can family practice improve access? In: Hopkins A, Bahl V, eds. Access to health care for people from black and ethinic minorities. London: Royal College of Physicians, 1993.

10 Carr-Hill RA, Rice N, Roland M. Socioeconomic determinants of rates of consultation in general practice based on fourth national morbidity survey of general practices. BMF 1996;312:1008-12.

11 Dicker A, Armstrong D. Patients' views of priority setting in health care: an interview survey in one practice. $B M \mathcal{F}$ 1995;311:1137-9.

12 Carr-Hill R, Place M, Posnett J. Access and utilisation of health care services. In: Sheldon T, Posnett J, eds. Concentration and choice in healthcare. London: Financial Times, 2000.

13 Wensing M, Jung HP, Mainz J, et al. A systematic review of the literature on patient priorities for general practice care. Part 1: Description of the research domain. Soc Sci Med 1998;47:1573-88.

14 Williams SJ, Calnan M. Key determinants of consumer satsfaction with general practice. Fam Pract 1991;8:237-42.

15 Hall J, Dornan MC. What patients like about their medical care and how often they are asked: a metaanalysis of the satisfaction literature. Soc Sci Med 1988;27:939.

16 Ben Sira Z. Lay evaluation of medical treatment and competence development of a model of the function of the physician's affective behavior. Soc Sci Med 1982;16:10139 .

17 Biehn JT, Molineux JE. Patient evaluation of physician performance. 7 Fam Pract 1976; 8:565-9.

18 Roter DL, Hall JA. Physician's interviewing styles and medical information obtained from patients. $f$ Gen Intern Med 1987;2:325-9.

19 Donovan JL. Patient decision making. The missing ingredient in compliance research. Int $\mathcal{F}$ Technol Assess Health Care 1995;11:443-55.

20 Ramsay J, Campbell JL, Schroter S, et al. The General Practice Assessment Survey (GPAS): tests of data quality and performance properties. Fam Pract 2000;17:372-9.

21 National Primary Care Research and Development Centre. General Practice Assessment Survey (GPAS) manual. Manchester: University of Manchester, 1999.

22 Wensing $\mathrm{M}$, Grol R, van Montfort $\mathrm{P}$, et al. Indicators of the quality of general practice care of patients with chronic illness: a step towards the real involvement of patients in the assessment of the quality of care. Quality in Health Care 1996;5:73-80.

23 Roland MO, Holden, J, Campbell SM. How to score the Genral Practice Assessment Survey (GPAS). Manchester: National Primary Care Research and Development Centre, University of Manchester, 1999 [website: http:// www.npcrdc.man.ac.uk/quality/download.htm].

24 Campbell JL, Ramsay J, Green J. Practice size: impact on consultation length, workload, and patient assessment of care. Br $\mathcal{F}$ Gen Pract 2001 (in press).

25 MacIntyre S, Ellaway A, Der G, et al. Do housing tenure and car access predict health because they are simply markers of income or self esteem? A Scottish study. 7 Epidemiol Community Health 1998;52:657-64.

26 Dale A, Marsh C. The 1991 census user's guide. London: HMSO, 1993.

27 Phillips D, Brooks F. Age differences in women's verdicts on the quality of primary health care services. $\mathrm{Br} \mathcal{F}$ Gen Pract 1998;48:1151-4.

28 Baker R. Characteristics of practices, general practitioners and patients related to levels of patients' satisfaction with consultations. Br 7 Gen Pract 1996;46:601-5.

29 Cartwright A, Anderson R. General practice revisited: a second study of patients and their doctors. London: Tavistock, 1981.

30 Royal College of General Practitioners. Information fact sheet 3: Workload. London: Royal College of General Practitioners, 1999.

31 Rogers A, Hassell K, Nicholas G. Demanding patients? Analysing the use of primary care. Buckingham: Open University Press, 1999.

32 Curtis S, Lawson K. Gender, ethnicity and self-reported health: the case of African-Caribbean populations in London. Soc Sci Med 2000;50:365-85.

33 Naish J, Brown J, Denton B. Intercultural consultations: investigation of factors that deter non-English speaking women from attending their general practitioners for cervical screening. BMF 1994;309:1126-8.

34 Lam T, Green J. Primary health care and the Vietnamese community: a survey in Greenwich. Health Soc Care Community 1996;2:293-9. 


\section{Appendix 1 The General Practice Assessment Survey (GPAS) $>$}

Descriptive characteristics and content of the nine GPAS scales and four individual items are shown in the table below.

\begin{tabular}{|c|c|c|c|}
\hline Scale/item & No of items & Response format & Item content \\
\hline \multirow[t]{2}{*}{ Access } & 7 & Evaluative & $\begin{array}{l}\text { Location, opening hours, phoning through to reception or the GP, } \\
\text { availability of specific or any GP, waiting times in surgery }\end{array}$ \\
\hline & 1 & Report & Same day urgent availability of GP \\
\hline Receptionists & 1 & Evaluative & Service provided by receptionists \\
\hline Continuity of care & 1 & Evaluative & Continuity of care provided by patient's usual doctor \\
\hline Technical care & 5 & Evaluative & $\begin{array}{l}\text { GP's medical knowledge, thoroughness of physical examination, } \\
\text { arranging tests, treatment prescribing, diagnosis }\end{array}$ \\
\hline \multirow[t]{2}{*}{ Communication } & 3 & Evaluative & GP's thoroughness asking questions, attention, explanations \\
\hline & 1 & Report & Frequency of leaving surgery with unanswered questions. \\
\hline Interpersonal care & 3 & Evaluative & $\begin{array}{l}\text { GPs spending time with patient, showing patience, showing caring } \\
\text { and concern }\end{array}$ \\
\hline Trust & 4 & Evaluative & $\begin{array}{l}\text { Trusting of GP's judgements, GP's truthfulness about medical } \\
\text { condition, GP's valuing your health above costs, overall trust in } \\
\text { GP }\end{array}$ \\
\hline Knowledge of patient & 3 & Evaluative & $\begin{array}{l}\text { GP's knowledge of patient's medical history, worries, responsibilities } \\
\text { at home/work }\end{array}$ \\
\hline Nursing care & 3 & Evaluative & Nurses' attention to patient, quality of care, explanations \\
\hline Referral & 1 & Report & Non-referral to a specialist when patient thought one was needed \\
\hline Coordination & 1 & Report & GP coordinates care that patient receives from outside the practice \\
\hline Recommend & 1 & Evaluative & Would patient recommend their usual doctor to family and friends \\
\hline Overall satisfaction & 1 & Evaluative & Patient's overall satisfaction with the practice \\
\hline
\end{tabular}

